\title{
Uma Justiça sem Lei e Corporativa: o Brasil de Vargas e a Criação da Justiça do Trabalho
}

\author{
Luciano Aronne Abreu*
}

Resumo: É frequente entre os historiadores brasileiros a visão de que a Era Vargas introduziu no Brasil um regime autoritário e nacionalista, inspirado especialmente no corporativismo fascista italiano. De outro lado, é também frequente entre os historiadores a opinião de que seus princípios corporativos não teriam sido completamente adotados pelo governo brasileiro, mas foram simples instrumentos para a dominação de classes. A esse respeito, sem negar a influência italiana e seu evidente caráter de dominação e instrumento de manutenção da ordem social, tem-se por objetivo analisar a legislação social e trabalhista da Era Vargas a partir de suas influências da sociologia jurídica americana, frequentemente negligenciada pela historiografia. Nesse sentido, são representativas as obras Problemas de Direito Corporativo (1938) e Problemas de Direito Sindical (1943), de Oliveira Viana.

Palavras-chave: Corporativismo. Justiça do Trabalho. Oliveira Viana. Autoritarismo. Sociologia Jurídica.

\section{Introdução}

É frequente entre os historiadores brasileiros a visão de que a chamada Era Vargas introduziu no país um modelo político nacionalista e autoritário, inspirado especialmente no corporativismo italiano. O principal exemplo, nesse sentido, seria a legislação social

\footnotetext{
* Professor do Departamento de História e do Programa de Pós-Graduação em História da PUCRS. Doutor em História Latino-Americana pela UNISINOS. Financiamento: CAPES. E-mail: Luciano.abreu@pucrs.br.
} 
varguista, muitas vezes referida como uma simples transposição para o Brasil da Carta del Lavoro, de Mussolini. Ao mesmo tempo, é também frequente entre esses historiadores a opinião de que os seus princípios corporativos teriam sido aplicados apenas parcialmente pelo governo brasileiro, como instrumento de controle dos trabalhadores pelas classes dominantes ligadas ao Estado.

A esse respeito, apenas a título de ilustração, pode-se citar o clássico estudo de Luiz Werneck Viana, Liberalismo e Sindicato no Brasil (1978), em que o autor afirma que o corporativismo estatal brasileiro jamais se realizou de forma plena, apesar da sua complexa estrutura institucional. Nesse período, diz ele,

[...] a linguagem corporativa reduziu-se aos pronunciamentos dos dirigentes políticos do Estado, e até isso por um lapso de tempo breve. Os institutos corporativos, contra a intenção visível do legislador, foram esvaziados de sua filosofia 'colaboracionista', convertendo-se em instrumentos de crua dominação de classes (1978, p. 225).

Essa mesma opinião pode ser também observada no estudo mais recente de Adalberto Cardoso, Estado Novo e Corporativismo (2007), para quem nos anos trinta o Estado passou a se constituir no lugar de formulação das normas e regras de uso do trabalho (legislação trabalhista) e das normas e regras de distribuição dos frutos do trabalho (legislação social), tendo como contrapartida a repressão ao movimento sindical. Em suas palavras, diz o autor, este tratou-se de um "[...] corporativismo maneta, porque fechado à voz dos trabalhadores nos mecanismos decisórios do aparelho de Estado" (CARDOSO, 2007, p. 113).

Já Evaldo Vieira, em seu também clássico estudo intitulado Autoritarismo e Corporativismo no Brasil, propõe-se a analisar não exatamente as possíveis práticas políticas corporativas do Estado Novo, e sim as mais importantes referências teóricas do corporativismo de Oliveira Viana, principal intelectual ligado ao regime de Vargas. Ainda assim, a exemplo de Werneck Viana e de Cardoso, deve-se ressaltar que também para Evaldo Vieira este modelo não chegou a se implantar, constituindo-se num simples instrumento de organização e controle da sociedade. 
Quanto às suas referências teóricas, considerando ser o ecletismo uma tendência da cultura brasileira na época de Oliveira Viana, o autor diz que as principais fontes do seu pensamento seriam as obras do romeno Manoilesco, dos franceses Perroux e Pirou, do italiano Panuzio e, ainda, dos juristas ligados à Escola Sociológica de Direito dos Estados Unidos, dentre os quais Roscoe Pound, Cardozo, Holmes e Brandeis. Destes, no entanto, Oliveira Viana faria uma leitura livre e se apropriaria apenas daquilo que se aproximasse de sua própria concepção de mundo, de caráter nacionalista e realista, sendo seu nacionalismo definido com base em comparações externas e o realismo por um peculiar processo de aculturação de doutrinas externas, conforme interpretação de Evaldo Vieira.

Desse modo, diz o autor, Oliveira Viana destacou de Manoilesco sua concepção de corporativismo, rejeitando sua definição totalitária do Estado; de Perroux, salientou sua afirmação dos direitos do grupo, da supremacia do coletivo, rejeitando sua concepção de Estado-colaborador; de Pirou, destacou a capacidade dos sindicatos de promoverem convenções coletivas, seu direito de autorregulamentação e de ditar normas a todos os membros da profissão; da Escola Sociológica de Direito dos Estados Unidos, seu realismo jurídico, e de Pound, em particular, seu conceito de justiça sem lei ${ }^{1}$. Nesses termos, portanto, Evaldo Vieira conclui que não havia uma teoria corporativista no Brasil, apesar do esforço empreendido nesse sentido por Oliveira Viana, cuja concepção de Estado Corporativo

[...] é uma face do Estado Autoritário. Aliás, ambos aparecem também sob a denominação de Estado Moderno, Estado Nacional e Estado Democrático. Mas qualquer que seja o seu nome, o Estado de Oliveira Viana baseia-se no máximo fortalecimento do Poder Executivo que representa a autoridade (VIEIRA, 1981, p. 131).

Por outro lado, sem negar seu caráter nacionalista e autoritário, bem como suas influências do fascismo italiano, outros autores discutem a própria validade de se aplicar o conceito de corporativismo 
estatal ao Estado Novo de Vargas e identificam na obra de Oliveira Viana e no seu modelo político proposto a influência de uma variada gama de intelectuais, inclusive de origem norte-americana, mas, ao contrário de Evaldo Vieira, sem ver na obra de Viana uma subjacente manipulação de suas fontes.

Nesse sentido, por exemplo, pode-se citar a obra A Armadilha do Leviatã: a construção do corporativismo no Brasil, de Vanda Maria Costa, em que a autora se propõe a analisar tal construção a partir dos seus processos interativos, os quais podem variar de acordo com os atores envolvidos e do próprio conteúdo da interação. Segundo ela, arenas de interesse específico, como legislação tarifária, legislação social e política industrial, e acordos necessários à implantação de políticas específicas podem dar surgimento a "[...] arranjos corporativos parciais que envolvem apenas grupos estratégicos, afetando, no entanto, os demais grupos não envolvidos nas barganhas e negociações”. Nesses casos, diz a autora, “[...] o corporativismo é um tipo de cooperação que envolve apenas aqueles atores coletivos mais organizados, mais fortes e com maior poder de barganha e negociação" (COSTA, 1999, p. 45). Em sua opinião, esse teria sido justamente o caso brasileiro, em que o modelo corporativo implantado durante os anos Vargas seria o resultado de um processo de negociação entre a burguesia industrial e o Estado, excluindo os trabalhadores.

A esse respeito, deve-se observar que Costa não exatamente nega a validade do conceito de corporativismo aplicado ao Estado Novo, e sim daquele corporativismo chamado estatal, ou seja, " [...] aquele no qual o Estado impõe sua própria solução aos problemas da ação coletiva", o que seria apropriado apenas para falar da organização dos trabalhadores (COSTA, 1999, p. 47). Já em relação às elites industriais, num contexto de autoritarismo político e de capitalismo atrasado, seria mais adequado o conceito de corporativismo societal, que corresponderia "[...] aos casos em que esses problemas [de ação coletiva] são solucionados pelos próprios atores em interação com o Estado" (COSTA, 1999, p. 47).

Ora, sendo o corporativismo societal resultado de um processo de negociação entre atores coletivos organizados, e não um projeto definido a priori e imposto por um grupo ao outro, a autora supõe que havia naquele contexto diferentes ideias ou propostas de 
mudança social e política no Brasil, todas elas de tendência corporativa, destacando-se as de Oliveira Viana, do Ministério do Trabalho Indústria e Comércio (MTIC) e dos industriais paulistas, expressas por meio da Federação das Indústrias de São Paulo (FIESP). De sua parte, Viana via o corporativismo como "um projeto essencialmente normativo", tratando-se de "[...] criar o conjunto de mecanismos necessários a garantir normas de justiça e progresso social" (COSTA, 1999, p. 54). Para o governo, “[...] o corporativismo era, antes de tudo, um programa de integração dos atores ao Estado, sob sua coordenação e vigilância" (COSTA, 1999, p. 52). Já os empresários paulistas, mais preocupados em encontrar soluções para os seus conflitos intraclasse, de concorrência, recusavam-se a reconhecer a legitimidade do lugar dos trabalhadores, conforme proposto pelo sistema jurídico de Oliveira Viana, e o equilíbrio de forças entre industriais e trabalhadores, sob o controle do Estado, conforme propunha o governo. Embora eles não definissem exatamente um projeto alternativo aos de Viana e do governo, dada a própria diversidade do seu grupo e de suas associações, Vanda Maria Costa observa que o corporativismo societal que então se implantou no Brasil "[...] correspondeu a soluções encontradas pelos capitalistas para seus conflitos intraclasse", recorrendo ao Estado como árbitro (1999, p. 147-148)2. Assim, conclui a autora, a legislação corporativa brasileira teria institucionalizado mecanismos que responderam a interesses estratégicos da classe patronal. O resultado desse jogo, portanto, teria sido a organização de um tipo de cooperação entre governo, patrões e trabalhadores "na medida justa dos interesses de frações da burguesia industrial; na consolidação da representação de classe, operária e patronal, e no fortalecimento da expansão do Estado, como sistema de dominação e máquina de ação (governo)" (COSTA, 1999, p. 181).

George Freitas de Araújo, por sua vez, em estudo intitulado Uma Análise sobre o Corporativismo em Oliveira Viana, admite a aplicação do conceito de corporativismo à obra desse autor e ao próprio Estado Novo, como se pode depreender de sua análise, bem como admite também suas influências do fascismo italiano. Por outro lado, porém, Araújo destaca a crítica de Viana ao caráter estatal do corporativismo fascista, embora não esteja preocupado 
precisamente em classificar o corporativismo de Oliveira Viana em estatal ou societal, mas em identificar e analisar suas variadas influências, tais como o pensamento de Manoilesco, a Doutrina Social da Igreja (DSI) e o já citado fascismo. Começando por este último, Araújo diz que Viana partilhava com o fascismo "a idéia de valorização das corporações, da coletividade frente ao indivíduo e da harmonia entre as classes sociais", ainda que criticasse seu totalitarismo, seu ideal belicista-expansionista e seu caráter estatal de partido único (ARAÚJO, 2010, p. 16). Quanto a Manoilesco, apesar de suas diferenças sobre as relações entre corporativismo e sindicalismo, Viana aproximar-se-ia do autor romeno em sua convicção da "inevitabilidade do corporativismo como solução à crise do liberalismo", valorizando as corporações como condição para a obtenção de uma determinada organização nacional, da harmonia entre as classes sociais e como uma nova forma de representação política, em detrimento do sufrágio universal e do sistema de partidos (ARAÚJO, 2010, p. 18-19). Já em relação à DSI, apesar de sua interpretação mais secular dos textos eclesiásticos, Viana teria partilhado com a Igreja de sua posição "conservadora, anticomunista e anti-socialista", bem como de sua visão de que o Estado tem um papel central na normatização da relação capital-trabalho (ARAÚJO, 2010, p. 20-21).

Já Rogério Dutra dos Santos, como indica o próprio título do seu estudo, Oliveira Viana e o Constitucionalismo no Estado Novo: corporativismo e representação política, também utiliza o conceito de corporativismo aplicado à obra de Viana e ao regime de Vargas. Nesse caso, porém, ainda que o autor não fuja da visão tradicional do corporativismo como justificativa para a redução dos poderes legislativos e para a sua concentração nas mãos do Presidente da República, ou seja, como simples forma de dominação, deve-se observar que o ponto mais relevante de sua análise se refere à influência da sociologia jurídica norte-americana na obra de Oliveira Viana e, por seu intermédio, na modernização do direito e da criação de uma Justiça do Trabalho corporativa no Brasil. A esse respeito, Santos observa ainda que a crítica ao formalismo do Direito não é exclusiva da tradição realista dos Estados Unidos, mas remonta também à tradição europeia e às " [...] correntes de pensamento que inserem elementos 
não formais no cotidiano da decisão judicial", destacando autores como os norte-americanos Brandeis e Pound e o alemão Schmitt, a quem dedica maior atenção em sua análise.

De sua parte, em seu estudo Os Inventores do New Deal. Sindicato nos Estados Unidos dos anos 1930, Flávio Limoncic destaca as possíveis proximidades e divergências entre os modelos norte-americano e brasileiro de relações entre Estado e sindicatos, especialmente nos tempos do New Deal e do Estado Novo de Vargas. Em relação aos Estados Unidos, diria Limoncic, o conceito de pluralismo sustenta-se mal quando entendido como "um sistema de representação dos interesses contraposto ao sistema corporativo". A esse respeito, diz ele, se o sistema político pluralista só deve responder às pressões dos grupos de interesses, sem se preocupar com a sua formação ou mesmo com a formulação de suas demandas, "[...] ele não se aplica em absoluto ao caso norte-americano". Ao contrário, enfatiza o autor, "[...] o Estado americano esteve sistematicamente longe de estar dissociado do reino dos interesses privados: ele não respondia aos inputs deste, mas estava preocupado com a formação mesma de tais inputs, principalmente no que se refere ao movimento sindical [...]" (LIMONCIC, 2003, p. 245-246).

Nesse mesmo sentido, em relação ao Brasil, o autor diria que o conceito de corporativismo, alternativo e contraposto ao de pluralismo, também não seria adequado quando aplicado à Era Vargas, dado seu caráter quase normativo, "[...] associando arranjos corporativos a ordens políticas estatocêntricas [...]", ou seja, “[...] a institucionalidade corporativa surge como emanada do Estado e a sociedade civil aparece como tendo uma capacidade meramente reativa à ação estatal, particularmente no que se refere ao corporativismo estatal" (LIMONCIC, 2003, p. 248). Assim, em lugar do corporativismo estatal, Limoncic sugere que a relação entre Estado e sindicatos no Brasil pode ser melhor compreendida a partir do conceito de pacto trabalhista, conforme definido por Ângela de Castro Gomes, o qual pressupõe que se essas relações "[...] compreenderam um componente coercitivo contra setores do sindicalismo brasileiro, compreenderam também um pacto com outros setores, cujas origens podem ser remontadas à Primeira República". Desse modo, diz o autor, deve-se considerar que as relações entre 
Estado e movimento sindical no pós-30 “[...] não teriam resultado em mera submissão ou perda de identidade deste, mas em uma troca orientada pela articulação de ganhos materiais com ganhos simbólicos" (LIMONCIC, 2003, p. 248-249). Em sua conclusão, que se aproxima daquela de Vanda Maria Costa ao se utilizar do conceito de corporativismo societal, a "[...] centralidade do Estado no Brasil não seria um ponto de partida, mas o resultado de um processo", dado que, no pacto trabalhista, tal centralidade seria atribuída "aos processos de formação do empresariado e do trabalho industrial e de construção institucional do Estado"; o resultado dessa pactuação social então realizada é que proporcionaria

[...] à burocracia estatal, centralidade na mediação dos interesses sociais e na condução do processo econômico, ao empresariado, acesso a instâncias decisórias do Estado e, ao trabalho industrial organizado, seu reconhecimento como ator político legítimo, além de redes de proteção social e acesso à Justiça do Trabalho (LIMONCIC, 2003, p. 254).

A partir de tais referências, por um lado, pode-se observar a comum preocupação dos autores citados em melhor compreender o modelo político brasileiro dos anos Vargas, admitindo seu caráter corporativo, autoritário e de dominação de classes, bem como a influência central de Oliveira Viana em sua definição. Por outro lado, porém, alguns desses autores negam o caráter absoluto desse modelo, de simples manipulação estatal, ainda que não haja entre eles uma proposta alternativa comum ao conceito de corporativismo estatal e que poucos deles tenham se dedicado à análise das possíveis influências intelectuais e teóricas do corporativismo de Oliveira Viana e do Estado Novo.

Ao longo desse estudo, portanto, tem-se por objetivo não exatamente fazer uma crítica historiográfica a respeito dessas temáticas, mas analisar a autorreferida influência da "Sociological Jurisprudence" norte-americana no pensamento de Oliveira Viana e, possivelmente, também no modelo de Justiça do Trabalho implantado no Brasil durante os anos Vargas, considerando-se ter sido Viana o autor do seu projeto. Para tanto, serão tomadas 
como principais referências as obras Problemas de Direito Corporativo (1938) e Problemas de Direito Sindical (1943), de Oliveira Viana, e An Introduction to the Philosopby of Law (1930), de Roscoe Pound.

\section{O Corporativismo de Estado segundo Viana: Breves Referências}

Em primeiro lugar, como bem destacou Evaldo Vieira, deve-se observar que não havia exatamente uma teoria do corporativismo nas obras de Oliveira Viana, mas uma peculiar definição e adequação dos seus princípios à realidade nacional. A esse respeito, porém, deve-se relativizar a lógica da manipulação que este autor atribui ao pensamento corporativo de Oliveira Viana, sugerindo que ele teria negado o principal e se apropriado do acessório das formulações teóricas de Manoilesco, Perroux, Pirou e Panuzio, de modo a adequá-las à nossa realidade 3 .

Ao contrário, talvez possa-se dizer que Oliveira Viana não estava mesmo preocupado em elaborar uma teoria corporativa original para o Brasil, mas tão somente em propor alternativas à nossa insolidariedade social e falta de sentimento coletivo, resultantes das condições próprias de nossa formação histórica, do nosso meio e da cultura de nosso povo, que impediam a formação de uma verdadeira nação no Brasil e o seu desenvolvimento. Nesse sentido, dada a tendência da cultura brasileira ao ecletismo nas primeiras décadas do século XX, conforme sugere o próprio Evaldo Vieira (1981, p. 96), pode-se dizer que o corporativismo não se definiu para Oliveira Viana como um modelo próprio e adequado à realidade nacional, mas apenas como um dos vários referenciais teóricos apropriados por Viana ao longo de sua obra ${ }^{4}$, ou, talvez, como um ideal a ser atingido. Com isso, não se pretende negar qualquer influência do corporativismo e de seus teóricos no pensamento de Oliveira Viana, mas tão somente indicar que este autor não exatamente propunha ao país a adoção de um modelo de corporativismo puro, misto ou mesmo "manipulado", como sugere Vieira, mas visava a solucionar os problemas anteriormente referidos a partir da adoção 
de um modelo político nacionalista e autoritário, que organizasse e regulasse a sociedade por meio dos sindicatos profissionais, da criação de uma legislação social e da Justiça do Trabalho.

A esse mesmo respeito, deve-se também relativizar a interpretação de Evaldo Vieira que define o Estado Corporativo de Oliveira Viana como sinônimo de Estado Autoritário, sendo este o elemento de identidade entre o Brasil legal e o Brasil real (VIEIRA, 1981, p. 68). De um lado, pode-se dizer que o autoritarismo de fato se constituiria para Viana no modelo de Estado mais adequado à realidade nacional, unindo o Brasil legal ao real; de outro lado, porém, pelo menos naquilo que diz respeito especificamente ao caso brasileiro, não parece ser muito preciso definir o seu modelo autoritário como sinônimo de corporativismo. Isso porque, como ver-se-á melhor adiante, Viana irá se referir em diferentes momentos de sua obra às tendências corporativas do Estado Novo e à construção desse modelo no país, ou seja, em sua própria avaliação, o Estado Corporativo seria mais um ideal a ser atingido do que uma realidade do Estado Novo. Ainda sobre estas questões, mas agora referindo-se especificamente aos sindicatos e à Justiça do Trabalho, Evaldo Vieira diria que "[...] a concepção de Estado Corporativo de Oliveira Viana é uma face do Estado Autoritário" (1981, p. 131), e não exatamente seu sinônimo, como antes havia sugerido. Assim, diz ele, a capacidade regulamentadora dos sindicatos e a competência normativa da Justiça do Trabalho dariam a estes órgãos um caráter público, com traços corporativos, embora este modelo não tenha de fato sido implantado no país.

Nesses termos, como acima indicado pela historiografia e como admite o próprio autor, deve-se a seguir analisar de forma mais específica as influências do corporatismo e da já citada sociologia jurídica norte-americana no pensamento de Oliveira Viana e na sua proposta de organização dos sindicatos e da Justiça do Trabalho, entendidos tanto como expressão do Estado nacionalista e autoritário brasileiro quanto como um ideal a ser atingido, considerando-se que o Estado Novo, em sentido estrito, não se definia efetivamente como um Estado Corporativo.

Quanto ao corporativismo, ao mesmo tempo em que toma como referência o caso europeu para destacar a tendência de sua época à especialização técnica, à organização das classes econômicas 
e ao declínio dos por ele chamados "parlamentos oniscientes", Oliveira Viana observa que o Brasil não estaria ainda preparado para adotar esse modelo, o qual talvez não fosse mesmo adequado à nossa realidade, sendo então necessário construir um modelo próprio. No primeiro caso, sobre as tendências corporativas de sua época, já em 1930, Oliveira Viana defendia claramente que "as grandes classes econômicas" deveriam se colocar em condições de exercer os poderes públicos no Brasil, onde a competência parlamentar deveria ser substituída pela competência técnica. Ao contrário da Europa, porém, Viana dizia que no Brasil ainda há muita gente que acredita com sinceridade "[...] que um mocinho qualquer, de anel de rubi no dedo, só pelo simples fato de acontecer ter sido nomeado deputado, fica por isso mesmo, sem mais nada, com a competência para discutir ou elaborar uma lei sobre a metalurgia do ferro ou sobre a profilaxia antipalúdica" (1930, p. 158).

$\mathrm{Na}$ Europa, ainda que o autor cite como exemplos dessa tendência corporativa os casos de vários países, aí incluídas Bélgica, França e Inglaterra "dos parlamentos onipotentes", como Viana a ela se refere, suas principais referências seriam ao caso italiano, em que "[...] os projetos saem diretamente desse Conselho Técnico para os órgãos executivos do governo, sem passarem, nem mesmo em visita de cortesia, pela grande assembléia tradicional" (1930, p. 167). No Brasil, ao contrário, toda obra legislativa e administrativa seria feita exclusivamente por sua elite que está no poder, sem qualquer tipo de intervenção ou colaboração das classes. Tal situação manifestar-se-ia, inclusive, na elaboração da legislação social brasileira, sendo as leis de acidentes, de férias, de regulamentação das horas de trabalho, de regulamentação do trabalho de menores e mulheres, de aposentadorias e de seguros operários, por exemplo, "obra privativa do governo". Em suas palavras, diria Viana, "[...] nunca se ouviu, nem ninguém julga que seja preciso ouvir, as duas grandes classes - a dos operários e a dos patrões - cujos interesses vão ser afetados de um modo decisivo por estas leis" (1930, p. 174-175).

De um lado, portanto, pode-se dizer que os países europeus citados serviriam de exemplo ao Brasil, sendo o caráter técnico e corporativo dos seus governos uma nova tendência legislativa 
dos Estados modernos uma nova etapa de seus desenvolvimentos, talvez uma espécie de "imperativo do século XX", como definiria Manoilesco. Por outro lado, contudo, destacando a inexistência de espírito corporativo e de organização de classes no Brasil, Viana diria que "[...] é bem possível que nenhum destes sistemas nos sirva e que tenhamos mesmo de engenhar um sistema nosso, ao nosso jeito, uma solução própria, adaptada ao nosso meio; como é possível também que não engenhemos solução ou sistema algum [...]", mas nos resignemos em aplicar em escala modesta estes "largos e ousados métodos de política contemporânea” (1930, p. 181-182).

No segundo caso, portanto, admitindo a inadequação dos modelos europeus ao caso brasileiro, assim como a possível incapacidade de nossa sociedade em adequá-los de forma autônoma à realidade nacional, Oliveira Viana irá propor, especialmente em suas obras Problemas de Direito Corporativo (1938) e Problemas de Direito Sindical (1943), um modelo próprio e adequado à realidade nacional de organização do Estado no Brasil, de tipo nacionalista e autoritário, uma espécie de "corporativismo de Estado", no dizer corrente da historiografia. A esse respeito, porém, ao mesmo tempo em que se referia às "tendências declaradamente corporativas" do regime constitucional de 1937, Oliveira Viana também afirmava a necessidade de darmos "execução aos seus preceitos relativos à organização sindical das nossas atividades profissionais e econômicas, como base da futura organização corporativa" (1943, p. 25). Ou seja, como anteriormente já se referiu, tal corporativismo constituía-se numa tendência determinada pelo próprio Estado, numa perspectiva de futuro para o Brasil, mas não exatamente numa realidade política e institucional do regime de Vargas.

Nesse sentido, com vistas à sua adequação à realidade brasileira e à possível execução dessas tendências corporativas, deve-se destacar a importância que Oliveira Viana atribui em suas obras aos sindicatos e à sua capacidade regulamentadora, bem como à Justiça do Trabalho e sua competência normativa. Pode-se dizer que o perfil atribuído por Viana a essas instituições expressaria, ao mesmo tempo, tanto seus traços corporativos quanto o caráter nacionalista e autoritário do Estado Novo de Vargas quanto ainda suas declaradas influências da "sociological jurisprudence" norte-americana. 
Refletir, portanto, sobre essas influências da sociologia jurídica americana no pensamento de Oliveira Viana e na sua definição dos sindicatos e da Justiça do Trabalho é avançar na compreensão do sentido do seu chamado Estado Corporativo, como ver-se-á a seguir.

\section{Viana, Pound, os sindicatos e a Justiça [sem lei] do Trabalho no Brasil}

Sobre sua proposta de criação da Justiça do Trabalho no Brasil, em polêmica com o então deputado Waldemar Ferreira ${ }^{5}$ quanto ao seu caráter normativo, Oliveira Viana diria que suas divergências não se deviam apenas a questões de técnica interpretativa da Constituição, mas a um conflito entre duas concepções do Direito: de um lado, a "velha concepção individualista" advinda do Direito Romano, do Direito Filipino e do Direito Francês, que nos teriam chegado através do Corpus Juris, das Ordenações e do Code Civil; de outro, "[...] a nova concepção nascida da crescente socialização da vida jurídica, cujo centro de gravitação se vem deslocando sucessivamente do indivíduo para o grupo e do grupo para a nação, compreendida esta como uma totalidade específica" (1938, p. 7).

Para exemplificar tais concepções e suas diferenças, o autor toma como referência o caso dos Estados Unidos, em que seus juristas adotariam um duplo método de técnica, a interpretação e a construção. Em suas palavras, sobre as regras da interpretação, Viana diz que o sentido da Constituição "[...] é o que resulta da sua letra, do seu conceito gramatical e lógico e do confronto com outros dispositivos [...]", enquanto as regras da construção iriam além desses critérios lógicos e históricos, incluindo também um "outro critério extrajurídico, ou metajurídico - porque de natureza política" (1938, p. 12). Os partidários do primeiro método, da "old school", de Corwin, seriam "puros intérpretes da lei, manejadores rigoristas e mecânicos das regras da interpretação". Já os partidários do segundo método, da "new school", da "sociological jurisprudence" de Llewellyn (Holmes, Brandeis, Stone, Cardozo), seriam espíritos pragmáticos para quem "[...] a Constituição é um instrumento de que a sociedade se utiliza para os seus fins de 
progresso e de ordem, uma construção plástica e dinâmica, cujo texto deve estar permanentemente vitalizado pelos influxos das realidades sociais [...]" (1938, p. 14). Nesse sentido, sobre as novas tendências do Direito moderno, diz Viana: 1) o juiz de hoje não está mais circunscrito ao texto da lei, mas “[...] é um órgão vivo de elaboração legal, com uma amplitude de poder no manejo dos textos que permite ser um verdadeiro legislador"; 2) o "Estado Legislador" deve admitir novas fontes de normas jurídicas, normas elaboradas pelos grupos sociais e pelas coletividades organizadas. Com isso, diz ele, "[...] alargam-se os horizontes da exegese 'interpretativa' e 'construtiva', até então restrita e constrangida exclusivamente no exame dos textos" (1938, p. 22).

Além disso, para justificar o caráter peculiar da sua Justiça do Trabalho e o papel por ele atribuído aos sindicatos, Viana tomaria ainda como importante referência o conceito de "Justiça sem lei", de Roscoe Pound, juiz da Suprema Corte de Nebraska e professor da Escola de Direito de Harvard. A esse respeito, porém, duas questões devem ser observadas antes que se passe a definir o sentido atribuído por Pound à lei e sua apropriação por Viana: por um lado, o fato de a obra do jurista americano estar associada à defesa da liberdade, estando inclusive disponível para consulta no site The Online Library of Liberty, mantido pela Liberty Fund $\mathrm{Inc}^{6}$, enquanto sua apropriação por Oliveira Viana se deu justamente no sentido de justificar seu modelo político autoritário e o caráter normativo da sua Justiça do Trabalho. Por outro lado, como indica o próprio título de sua obra, Pound propõe-se a refletir teoricamente sobre a "filosofia da lei”, em seu sentido geral, enquanto Viana apropria-se desses princípios para aplicá-los na justificação de um regime político e de um modelo específico de Justiça, como acima referido.

Ao longo de sua obra, que se constitui numa versão escrita das conferências proferidas por Pound na Escola de Direito de Yale, entre os anos de 1921 e 1922, o autor discorre sobre diferentes questões relativas à filosofia da lei, dentre as quais se incluem o "fim da lei", no sentido das suas finalidades, e a "aplicação da lei", que foram mais diretamente apropriadas para os fins propostos por Oliveira Viana e que, portanto, serão aqui enfatizadas nas referências a seguir. 
Quanto aos fins da lei, Pound observa que a principal discussão filosófica a seu respeito, desde que os filósofos gregos começaram a refletir sobre as bases da sua autoridade, refere-se à natureza da lei, que se constituiria num debate de ordem mais política que jurídica. Na história do Direito, no estágio da igualdade e dos direitos naturais, o autor diz que a teoria do Direito Natural parecia responder à questão dos fins da lei como uma garantia daqueles direitos, devendo ela se estender o mínimo possível para não restringir a liberdade do homem (POUND, 1930, p. 20). Nesse sentido, diz ele, em não havendo teorias positivas a respeito da elaboração das leis, sempre associadas à restrição da liberdade ou à imposição de normas, o século XIX teria sido consciente da necessidade de uma teoria que respondesse aos seus fins.

De um modo geral, após identificar doze diferentes concepções acerca da natureza da lei ${ }^{7}$, Pound observa que há entre elas três aspectos em comum: 1) seus fundamentos iriam além do alcance dos desejos individuais do homem; 2) a definição de um modo determinado e mecânico de procedimento, a partir de um ponto de partida absoluto; 3) a definição de um sistema de ordenamento da conduta humana e de ajustamento de suas relações baseado em um processo absoluto. A seguir, em contraponto a tais concepções sobre as origens e a natureza da lei, Pound identifica três diferentes visões na história do Direito a respeito dos seus fins: 1) a lei existe para manter a paz a qualquer preço, já que as necessidades de dada sociedade são satisfeitas pela garantia de sua segurança; 2) a lei existe para manter o status social, constituindo-se apenas num instrumento para garantir a ordem e manter cada indivíduo no seu lugar; 3) a lei existe para garantir aos indivíduos sua máxima liberdade de julgamento. Além destas, observa o autor, uma quarta visão sobre suas finalidades estaria se afirmando em princípios do século XX, baseada na ideia de que os limites da ação humana são expressos pela razão e pela moral, deslocando assim a concepção dos fundamentos da lei da igualdade natural para os direitos naturais. Nesse sentido, os limites da atividade humana tinham por garantia as qualidades morais do homem, que garantiriam a ele o direito de ter e fazer certas coisas. Estes seriam seus direitos naturais e a lei existiria apenas para garantir e tornar esses direitos 
efetivos, não devendo haver nenhum outro tipo de restrição a não ser o de compelir os homens a respeitar o direito dos seus semelhantes (POUND, 1930, p. 26-27).

Para Pound, no entanto, mesmo esta última concepção não estaria mais de acordo com o novo contexto social e político que então se vivia, de permitir o máximo de liberdade ao julgamento individual num mundo onde não havia mais continentes a descobrir e os recursos naturais já haviam sido explorados, sendo a conservação o que havia restado de mais viável. Afinal, num mundo populoso e de recursos escassos, a máxima liberdade de julgamento começaria a produzir mais conflitos do que evitá-los. Em tais condições, alguns juristas estariam pensando nos fins da lei, não mais em relação ao máximo de liberdade para satisfazer ou equalizar os desejos dos homens, mas para equalizar ou ao menos harmonizar suas necessidades, o que os levou a pensar nos problemas da ética, da jurisprudência e da política como um problema de valores. Ou seja, como um problema de encontrar critérios de valores relativos de interesses. Em termos jurídicos e políticos, diz Pound, “[...] they [the jurists] saw we must add practical problems of the possibility of making interests effective through governmental action, judicial or administrative" (POUND, 1930, p. 28).

A lei, portanto, deixaria de ser vista como um conjunto de regras a serem aplicadas a diferentes situações, ainda que análogas, para se constituir num instrumento flexível de resolução de conflitos e de satisfação das necessidades humanas, por meio da ação judicial ou administrativa dos governos. Porém, em não havendo critérios absolutos de valor, caberia ao jurista reconhecer um dado problema e perceber nele um problema à garantia de todos os interesses da sociedade, sendo o fim da lei nada menos do que fazer o que for preciso para alcançar a satisfação das necessidades humanas. Muitas vezes, no entanto, os juristas enfrentam para isso limites que lhes são impostos pelas próprias ferramentas com que trabalham, sendo então necessário improvisá-las. Nesses termos, pode-se dizer que Pound expressa não apenas sua visão a respeito dos fins da lei, mas também sua preocupação a respeito da sua aplicação, como ver-se-á a seguir. Em suas palavras, diz ele: 
Experience has shown abundantly how futile legal machinery may be in its attempts to secure certain kinds of interests. What I do say is, that if in any field of human conduct or in any human relation the law, with such machinery as it has, may satisfy a social want without a disproportionate sacrifice of other claims, there is no eternal limitation inherent in the nature of things, there are no bounds imposed at creation, to stand in the way of its doing so (POUND, 1930, p. 30-31).

Quanto à aplicação da lei, considerando a incapacidade do seu instrumental legal de satisfazer as necessidades da sociedade em muitos campos das relações humanas sem provocar enormes sacrifícios em outros, Pound diz que não devem haver então limites à criação de novos caminhos para que se possa atingir suas finalidades. Em sua opinião, ao contrário da tradicional concepção de separação rígida de funções entre os poderes, Pound diz que "[...] lawmaking, administration and adjudication cannot be rigidly separeted" (1930, p. 33). Em sua concepção tradicional, a aplicação da lei estava ligada à sua adjudicação pelo Judiciário, que se limitava em encontrar no sistema legal a melhor lei, interpretá-la e aplicá-la ao caso então em julgamento. Porém, como alerta o autor, muitos casos não são tão simples e mais de um texto pode ser a ele aplicado, levando-o a afirmar que em tais situações as funções judiciais e legislativas andam juntas. Diz ele: "But from de nature of the case it cannot make laws so complete and all-embracing that the judicial organ will not be obliged to exercise a certain lawmaking function also" (POUND, 1930, p. 33).

Em sua concepção, pode-se dizer que Pound não apenas critica esta rígida separação de funções entre os poderes como também atribui um papel central ao Judiciário para garantir a harmonia e a satisfação das diferentes necessidades do homem em sociedade. Isso porque, em sua concepção do sentido da lei e de sua aplicação, a interpretação da lei, que se constituiria na principal função do Judiciário, corre muitas vezes no mesmo sentido da sua elaboração ou da sua aplicação, como pode-se visualizar na representação a seguir. A esse respeito, diz Pound, 
[...] as interpretation on the one side runs into lawmaking and so the judicial function runs into the legislative function, on the other side interpretation runs into application and so the judicial function runs into the administrative or the executive (POUND, 1930, p. 34).

\section{Quadro 1 - Representação das relações entre o Judiciário e os Poderes Executivo e Legislativo, tendo por base seu poder e autonomia para interpretar as leis, segundo Roscoe Pound.}

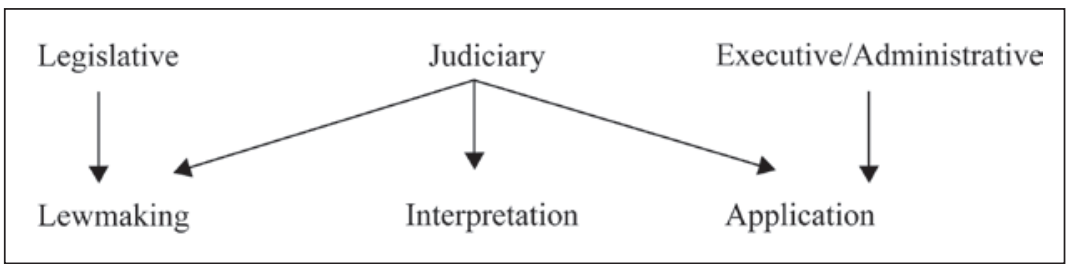

Fonte: Elaborado pelo autor.

Nesses termos, observa o autor, novos caminhos para a aplicação da lei estariam sendo criados ou admitidos pelo sistema legal anglo-americano, de modo a resolver casos particulares não definidos em lei, mas sem ignorar seus princípios gerais ${ }^{8}$. Dentre estes, Pound refere-se à tendência crescente nos Estados Unidos de individualização da aplicação da lei por meio de diversas agências, como a justiça administrativa, as cortes especiais, as comissões, ou mesmo através de uma interpretação mais ampla e individualizada da lei pelos tribunais do país, constituindo-se o que o autor define como uma "justiça sem lei", em oposição à chamada "justiça de acordo com a lei", mais adequada aos períodos de estabilidade, e não de transição. Assim, ao admitir esses novos canais de aplicação da lei, sendo esta entendida não como um conjunto detalhado de regras, mas como princípios gerais para a argumentação jurídica, Pound diz ser necessário admitir também uma teoria que reconheça como legítimo o caráter administrativo das funções judiciais e que a individualização da aplicação da lei não é menos importante que o teor dos seus princípios. 
Sobre esses novos Tribunais Administrativos e suas funções, Pound diz que suas ações e decisões poderiam se referir a questões muito amplas e variadas, tais como

[...] the regulation of public utilities, apportionment of the use of the water of running streams among different appropriators, workmen`s compensation, the actual duration and nature of punishment for crime, admission to and practice of professions and even of trades [...] (POUND, 1930 , p. 42).

Esses tribunais, que representam uma forma de reação à rígida aplicação da lei nos períodos de estabilidade, são também mais efetivos para regular a conduta das empresas e seus conflitos e para melhor ajustar a administração à lei, evitando a ineficiência e o desperdício, a perda de tempo e de dinheiro sob uma mera etiqueta de justiça. Em síntese, conclui Pound:

Where the calls is for individuality in the product of the legal mill, we resort to standards. And the sacrifice of certainty in so doing is more apparent than actual. For the certainty attained by mechanical application of fixed rules to human conduct has always been ilusory (POUND, 1930, p. 44).

Das questões anteriormente referidas sobre os fins da lei e sua aplicação, pode-se dizer que sua concepção social-utilitarista, como o próprio Pound se refere, especialmente em relação à sua definição de uma "justiça sem lei” e à defesa de um sistema judicial com funções também de caráter administrativo, daria margem à peculiar interpretação de Oliveira Viana, com vistas a adequar seus preceitos para justificar a prática política autoritária brasileira e sua criação de uma Justiça do Trabalho de tipo normativo.

No caso brasileiro, porém, ao contrário do que Pound dizia ser uma tendência nos Estados Unidos, Oliveira Viana observa que nossos centros de cultura jurídica não estariam manifestando as concepções relativas às novas fontes do Direito positivo, nem mesmo os novos horizontes da exegese constitucional abertos pela metodologia 
da "new school" norte-americana. Em suas palavras, diz o autor, "[...] no tocante, por exemplo, à interpretação dos textos constitucionais não foi feita aqui ainda uma distinção muito clara entre construção e interpretação" (1938, p. 27). O melhor exemplo disso seria exatamente o "[...] modo porque estão sendo interpretados e entendidos os dispositivos da nova Constituição relativos à organização e competência da Justiça do Trabalho" (1938, p. 29). De acordo com seus próprios conceitos, talvez se possa dizer que Oliveira Viana associa a técnica da interpretação jurídica ao "idealismo utópico", e a técnica da construção ao "idealismo orgânico". Nesses termos, portanto, é que o autor irá propor a criação no Brasil de uma Justiça do Trabalho de caráter normativo, não mais limitando à atuação dos juízes ao texto estrito da lei, e, ao mesmo tempo, admitindo a validade de novas fontes de normas jurídicas, elaboradas por coletividades organizadas, como os sindicatos, por exemplo.

Sobre a questão normativa da Justiça do Trabalho, que se remeteria à "justiça sem lei" e aos tribunais administrativos de Pound, Oliveira Viana destaca que esta se justificaria, de um lado, por necessidades próprias da administração pública; e, de outro, por serem suas decisões sempre relativas a conflitos coletivos.

No primeiro caso, diz Viana, negar seu caráter normativo sob alegação do princípio da não delegação de poderes ${ }^{9}$ poderia tornar impossível a administração da coisa pública. Em sua opinião, o “[...] mandamento proibitivo quebra-se em face dos próprios imperativos da prática administrativa" (1938, p. 40), conforme o autor observa ocorrer em países como Itália, Inglaterra, Estados Unidos, Alemanha, Áustria e Austrália, que ele chama de "mundo civilizado". Em tais nações, diz Viana, estaria ocorrendo um movimento geral de descentralização das atividades do Estado, dada a crescente complexidade das funções do Estado moderno, suas tendências totalitárias ou universalistas e a necessidade de reagir contra a descentralização geográfica, o que implicaria também uma descentralização jurídica (1938, p. 48-49).

Além da Justiça do Trabalho, Oliveira Viana destaca ainda as Convenções Coletivas ${ }^{10}$ negociadas por empresários e sindicatos como outro importante mecanismo de regulação das relações de trabalho e de solução dos seus conflitos. A esse respeito, 
talvez se possa relacionar seu sentido àquele atribuído por Pound às diferentes agências de aplicação da lei nos Estados Unidos. Estas colocar-se-iam como uma primeira etapa das negociações entre patrões e operários, que seriam depois reconhecidas pela Justiça ou por ela normatizadas, caso não houvesse acordo prévio entre as partes. Sobre tais Convenções, que podem ser entendidas como uma nova fonte de norma jurídica, conforme os princípios da "new school" norte-americana, deve-se observar a importância dos sindicatos em sua elaboração e o problema do seu campo de aplicação, como Viana refere-se ao alcance e grau de obrigatoriedade de suas normas. Sobre este último ponto, diz o autor, as verdadeiras Convenções seriam aquelas cujas decisões se referissem a todos os operários de uma categoria "ou mesmo para as categorias conexas" (1938, p. 162).

No caso brasileiro, porém, ao contrário dos Estados Unidos, as convenções coletivas não seriam exatamente resultado de uma livre negociação entre empresários e sindicatos, nem mesmo se estenderiam com facilidade a toda uma categoria, dada a histórica insolidariedade social brasileira e sua consequente ausência de um sentimento coletivo e nacional entre as classes. Nesses termos, portanto, caberia ao Estado brasileiro manter o controle sobre a atividade convencional e normativa dos grupos, estimulando e regulando também a sua criação e o seu funcionamento, enquanto aos sindicatos caberia o papel de educar o nosso povo para a cultura da solidariedade, fazendo-o passar da fase de "massa" para a de "comunidade", e, talvez, para a de "comunhão". Em suas palavras, diz Viana, só os sindicatos poderiam constituir e desenvolver em nosso povo "[...] aquilo que as forças da nossa história não permitiram que constituíssemos e desenvolvêssemos: os hábitos de cooperação e de ação coletiva, bem como a consciência do enorme poder da solidariedade social" (1943, p. IX).

Tais sindicatos, portanto, constituir-se-iam para Viana em importantes meios de educação e organização da sociedade brasileira e, ao mesmo tempo, em novos canais de atuação das diferentes classes econômicas junto ao Estado. Assim, de acordo com o que Viana dizia serem as condições e necessidades próprias da realidade brasileira, a legislação sindical por ele proposta determinou a criação de sindicatos únicos por ofício no Brasil. Em sua opinião, o sindicato 
de ofício seria o ideal "para a organização de povos como o nosso, sem instituições, nem tradições de solidariedade econômica ou profissional”, visto que sua homogeneidade de composição permitiria "[...] cristalizar mais rapidamente, entre os seus associados, uma forte consciência de unidade e de grupo e, em conseqüência, um sentimento mais lúcido e militante dos interesses coletivos da categoria a que pertencem" (1943, p. X). Quanto à unicidade sindical, esta justificar-se-ia para Viana porque a legislação reconheceu os sindicatos e suas Convenções Coletivas como válidas para toda a categoria profissional, e não apenas para os seus associados. Do contrário, diz ele, "[...] teríamos um caso de dupla personalidade legal. [...] O fato de ter a Constituição dado às Convenções Coletivas o caráter de um regulamento da categoria implica, sem dúvida, no reconhecimento do sindicato único". Ou, então, diz o autor, “[...] teríamos a possibilidade de várias convenções coletivas regulando diversamente a mesma matéria para a categoria inteira - o que seria absurdo" (1943, p. 4-5).

Em tais condições, de acordo com os princípios anteriormente referidos, os sindicatos no Brasil não seriam apenas associações privadas, mas assumiriam também atributos de direito público, tornando-se uma associação sui generis, "[...] colocada numa situação que a situa abaixo das instituições administrativas do Estado, mas acima do vasto mundo das associações privadas, sobre as quais o Estado não tem propriamente nenhum interesse de controle direto e imediato" (1943, p. 6-7).

Face ao exposto, ainda que não se negue a influência dos ideais corporativos na obra de Oliveira Viana e no próprio modelo político do Estado Novo, pode-se dizer que este regime de fato não se define como corporativista, ao menos conforme os princípios estritos do corporativismo puro, misto ou mesmo "manipulado", como a ele muitas vezes se refere a historiografia. Do mesmo modo, mais uma vez sem negar seus traços corporativos, pode-se ainda afirmar que o caráter normativo da Justiça do Trabalho e os sindicatos únicos por ofício também não se constituíam numa distorção ou num modelo capenga de corporativismo, mas num modelo conscientemente proposto por Oliveira Viana, inspirado pela sociologia jurídica norte-americana e baseado no conceito de 
"justiça sem lei”, de Pound, com o objetivo de subordinar a sociedade ao Estado autoritário brasileiro, dadas às condições supostamente peculiares da sua sociedade.

\section{A JUSTICE WITHOUT LAW AND CORPORATIVE: THE BRAZIL OF VARGAS AND THE CREATION OF LABOUR JUSTICE}

Abstract: It is frequent among Brazilian historians the interpretation that in Vargas Era it was introduced in the country a nationalist and authoritarian regime, inspired specially in the corporativism of Italian fascist regime. On the other hand, it is also frequent between these historians the opinion that the principles of corporativism would not be completely adopted by Brazilian government, but were simple instruments for class domination. About this subject, however, without denying its Italian influence and its evident character of domination and instrument to maintain the social order, we have also to analyze the social and labour legislation of Vargas regime including its influences of the American sociological jurisprudence, frequently neglected by historiography. In this sense, the books "Problemas de Direito Corporativo (1938)" and "Problemas de Direito Sindical (1943)", of Oliveira Viana, are representative.

Keywords: Corporatism. Labour Justice. Oliveira Viana. Authoritarianism. Sociological Jurisprudence.

\section{Notas}

${ }^{1}$ Estas ideias e relações são discutidas sistematicamente por Evaldo Vieira ao longo do capítulo dois de sua obra Autoritarismo e Corporativismo no Brasil. São Paulo: Cortez, 1981.

${ }^{2}$ Tal situação, na interpretação de Vanda Maria Costa, ao mesmo tempo em que solucionaria os conflitos intraclasse dos industriais paulistas e asseguraria seus interesses em detrimento dos trabalhadores, os levaria a cair na chamada "armadilha do Leviatã", citando metáfora de Martins Hollins, segundo a qual as razões que levam ao pacto sobre a ordem social são as mesmas que levam ao rompimento do pacto e à desordem. Em suas palavras, assim a autora explica a armadilha aos empresários: "Aprisionados aos impasses produzidos por sua própria racionalidade, são levados [os empresários] a recorrer ao Estado para superá-los. Em que consiste, nesse caso, a armadilha? Recorrendo ao Estado como árbitro dos seus conflitos intraclasse - fundamentalmente conflitos de mercado - a demanda pela intervenção tende a se acentuar face a cada conflito 
no mercado. Intervenções tópicas se sucedem, substituindo a competição no mercado pela competição pela proteção do Estado. Está montada a armadilha, através da qual o Estado passa a ocupar a posição privilegiada de poder selecionar os atores estratégicos para a implantação de seus próprios projetos" (COSTA, 1999, p. 147-148).

${ }^{3}$ A esse respeito, ver: VIEIRA, Evaldo. Autoritarismo e Corporativismo no Brasil. São Paulo: Cortez, 1981, cap. 2.

${ }^{4}$ Ao longo de sua obra, pode-se ainda perceber muitas referências de Oliveira Viana a diferentes teorias políticas, das elites, sociológicas e eugênicas, por exemplo. ${ }^{5}$ A obra Problemas de Direito Corporativo compõe-se de uma série de artigos publicados por Oliveira Viana no Jornal do Comércio, em resposta às críticas do deputado Waldemar Ferreira ao seu projeto de organização da Justiça do Trabalho no Brasil, enviado para aprovação na Câmara dos Deputados ainda antes da instalação do regime do Estado Novo. Em suas próprias palavras, diz Viana: "tendo participado da organização do projeto, achei que me corria o dever de vir a público defendê-lo. [...] Nesse sentido, escrevi uma série de artigos, que vieram a lume no Jornal do Comércio, e que são exatamente os sete estudos que compõe este livro" (1938, p. 5).

${ }^{6}$ Ao longo desse estudo, todas as referências da obra An Introduction to the Philosophy of Law, de Roscoe Pound, serão feitas a partir da sua versão em pdf disponível no site The Online Library of Liberty, mantido pela Liberty Fund Inc: http://files.libertyfund.org/files/2222/Pound_1502_EBk_v6.0.pdf. Em suas próprias palavras, tal fundação "is a private, non-profit, educational foundation established in 1960 to encourage study of the ideal of a society of free and responsible individuals" (The Online Library of Liberty, p. 1).

${ }^{7}$ A esse respeito ver: POUND, Roscoe. An Introduction to the Philosophy of Law. Yale University Press, 1922. Acessible in Online Library of Liberty: http://oll. libertyfund.org (pdf version), cap. II. Acesso em: maio e junho de 2012.

${ }^{8}$ A respeito da relação entre a individualização da lei e seus princípios gerais, diz Pound: "Tipically administrative treatment of a situation is a disposition of it is a unique ocurrence, an individualization whereby effect is given to its special rather tha to its general features. But administration cannot ignore the universal aspects of situations without endangering the general security" (1930, p. 34).

${ }^{9}$ Em sua crítica ao caráter normativo da Justiça do Trabalho, o deputado Waldemar Ferreira dizia que este contrariava os princípios de nosso direito judiciário tradicional e da própria Constituição de 1934. No primeiro caso, argumentava que é regra do direito que as sentenças de qualquer juiz só obrigam os litigantes, e não a terceiros que não participaram do pleito. No segundo, alegava que atribuir tal competência normativa à Justiça do Trabalho implicaria lhe atribuir poderes para editar normas gerais, o que se configuraria numa delegação de legislativos ao 
Judiciário. A esse respeito, ver: VIANA, Oliveira. Problemas de Direito Corporativo. Rio de Janeiro: José Olympio, 1938, cap. II.

${ }^{10}$ A respeito das Convenções Coletivas de Trabalho, Oliveira Viana observa que não se deve confundi-las com os Contratos Coletivos de Trabalho. Em suas palavras, diz: "O ponto de diferenciação entre estas duas espécies está precisamente na natureza do objeto de cada uma. O objeto do contrato coletivo é distinto do da convenção coletiva. Quando um patrão ou sindicato de patrões conchava com um grupo de empregados ou sindicato de empregados um contrato coletivo, o que eles contratam é trabalho, é serviço, é energia aplicada, é esforço produtivo, físico ou intelectual, desenvolvido não mais por um único trabalhador, como no contrato individual, mas por uma pluralidade deles, visando um objetivo comum" (1938, p. 148-149). Já na Convenção Coletiva, diz Viana, "a situação é outra, inteiramente diferente. Não se contratam serviços e sim normas (preceitos, cláusulas, etc.), pelas quais se deverão reger os futuros contratos de trabalho, sejam individuais, sejam coletivos" (1938, p. 150-151).

\section{Referências}

CARDOSO, Adalberto. Estado Novo e Corporativismo. Locus: Revista de História. Juiz de Fora, v. 13, n. 2, 2007.

DIEHL, Autor Antônio. Estado Novo: Corporativismo e Círculos Operários. Revista de Estudos Ibero-Americanos. Porto Alegre, v. 13, n. 1, p. 19-35, 1987.

DINIZ, Eli. Engenharia Institucional e Políticas Públicas: dos Conselhos Técnicos às Câmaras Setoriais. In: PANDOLFI, Dulce (Org.). Repensando o Estado Novo. Rio de Janeiro: FGV, 1999.

MANOILESCO, Mikhail. Tradução de Azevedo Amaral. O Século do Corporativismo. Rio de Janeiro: José Olympio, 1938.

NUNES, Edson. A Gramática Politica do Brasil: clientelismo, corporativismo e insulamento burocrático. Rio de Janeiro: Jorge Zahar, 2007.

POUND, Roscoe. An Introduction to the Philosophy of Law. New Haven: Yale University Press, 1922. Accessible in Online Library of Liberty. Disponível em: $<$ http://oll.libertyfund.org> pdf version. Acesso em: maio/jun. 2012.

ROMITA, Arion. Justiça do Trabalho: produto do Estado Novo. In: PANDOLFI, Dulce (Org.). Repensando o Estado Novo. Rio de Janeiro: FGV, 1999.

SOUZA, Francisco Martins de. Raízes Teóricas do Corporativismo Brasileiro. Rio de Janeiro: Tempo Brasileiro, 1999. 
STEPAN, Alfred. Estado, Corporativismo e Autoritarismo. Rio de Janeiro: Paz e Terra, 1980.

VIANA, Luiz Werneck. Liberalismo e Sindicato no Brasil. Rio de Janeiro: Paz e Terra, 1978.

VIANA, Oliveira. Populaçẽes Meridionais do Brasil. São Paulo: Monteiro Lobato \& Cia., 1920.

. Problemas de Direito Corporativo. Rio de Janeiro: José Olympio, 1938. . O Idealismo da Constituição. 2. ed. São Paulo: Cia. Editora Nacional, 1939. . Problemas de Direito Sindical. São Paulo: Coleção de Direito do Trabalho. Gráfica Editora Brasileira, 1943.

VIEIRA, Evaldo. Autoritarismo e Corporativismo no Brasil: Oliveira Viana \& Companhia. São Paulo: Cortez, 1981.

Recebido em: 05/05/2013.

Aprovado em: 06/06/2013. 